Velden, P.G. van der, Kleber, R.J., Grievink, L., Yzermans, J.C. Confrontations with aggression and mental health problems in police officers: the role of organizational stressors, life-events and previous mental-heoft problems. Psychological Trauma: Theory, Research, Practice, and Policy: 2010, 2(2), 135-144

\begin{tabular}{|l|l|}
\hline $\begin{array}{l}\text { Postprint } \\
\text { Version }\end{array}$ & 1.0 \\
\hline Journal website & $\underline{\text { http://psycnet.apa.org/?\&fa=main.doiLanding\&doi=10.1037/a0019158 }}$ \\
\hline Pubmed link & $10.1037 / \mathrm{a} 0019158$ \\
\hline DOI &
\end{tabular}

This is a NIVEL certified Post Print, more info at http://www.nivel.eu

\title{
Confrontations With Aggression and Mental Health Problems in Police Officers: The Role of Organizational Stressors, Life-Events and Previous Mental Health Problems.
}

\author{
PETER G. VAN DER VELDEN ${ }^{1}$ AND ROLF J. KLEBER ${ }^{1}$, LINDA GRIEVINK ${ }^{2}$ AND JORIS C. YZERMANS ${ }^{3}$ \\ ${ }^{1}$ Institute for Psychotrauma (IVP). \\ ${ }^{2}$ National Institute for Public Health and the Environment (RIVM). \\ ${ }^{3}$ Netherlands Institute for Health Services Research (NIVEL).
}

The extent to which the frequency of facing aggression incidents is associated with mental health problems among police officers when organizational stressors, life-events, and previous mental health problems are taken into account is unclear. To elucidate this data from a longitudinal study of police officers was analyzed $(N=473)$. Mental health problems (MHPs) are here defined as severe anxiety, depression, hostility, burnout symptoms, and/or sleeping problems according the SCL-90-R and MBI.

All MHPs were assessed at baseline and 27 months later. Logistic regression showed that serious threat was statistically significant associated with MHPs at follow-up among officers without MHPs at baseline, but not among those with MHPs at baseline. However, stepwise logistic regression showed that serious threat and/or physical aggression were not independently associated with MHPs at follow-up. Organizational stressors, that is, problems with colleagues were independent predictors in all analyses. Among the total study sample, previous MHPs were the strongest independent predictors. These findings suggest superiors should attend to the mental health, organizational stressors and life-events of their officers regularly and not only following critical incidents at work.

Police officers are, because of the nature of their work, at risk of falling victim to serious threats and physical aggression (Andrew et al., 2008; Brown, Fielding, \& Grover, 1999; BZK, 2006; Carlier, Lamberts, \& Gersons, 1997; Stephens \& Miller, 1998). For instance in 2005, 53\% of all Dutch police officers were confronted once or more with physical violence aimed at themselves (BZK, 2006). Insight into the effects of aggression incidents on mental health and factors related to recovery may help to identify relevant (early) interventions to reduce mental health problems (MHPs).

In general, a minority of police officers has been found to suffer from MHPs. For instance, a recent comprehensive nationwide questionnaire survey of 3,272 Norwegian police officers (Berg, Hem, Lau, \& Ekeberg, 2006) demonstrated that $11.2 \%$ had severe anxiety symptoms and $8.2 \%$ showed severe depression symptoms.

A similar prevalence of severe depression symptoms (8.6\%) was found, although using a different instrument, among a smaller representative sample of New York police (Andrew et al., 2008).

In addition, of the last mentioned Group 30.5\% reported moderate to severe levels of PTSD symptoms (reexperiencing and avoidance reactions). A Dutch study found that $\sim 7 \%$ of the participating officers met the 
Velden, P.G. van der, Kleber, R.J., Grievink, L., Yzermans, J.C. Confrontations with aggression and mental health problems in police officers: the role of organizational stressors, life-events and previous mental-health problems. Psychological Trauma: Theory, Research, Practice, and Policy: 2010, 2(2), 135-144

criteria for current posttraumatic stress disorder (PTSD) and that 34\% had lower levels of PTSD symptomatology (Carlier, Lamberts, \& Gersons, 1997). The significance of these mental health problems is (besides personal suffering and diminished quality of life) also related to other aspects of functioning (cf.

Agolla, 2009). For example, these symptoms have been associated with reduced job satisfaction and functional impairment (North et al., 2002), increased substance use (van der Velden \& Kleber, 2009), sick leave (Berg et al., 2006), the use of force (Kop \& Euwema, 2001), and parenting styles that have a negative influence on of children's adjustment (cf. Jordan et al., 1992).

Research has indicated that intentional (violent) events generally lead to poorer levels of health than nonintentional events (Kessler, Sonnega, Bromet, Hughes, \& Nelson, 1995), and that the frequency of incidents involving confrontations with aggression is associated with, for instance, (symptoms of) anxiety, depression, hostility, burnout, and sleeping problems among affected employees (Evers, Tomic, \& Brouwers, 2002; Miller-Burke, Attridge, \& Fass, 1999; van der Velden \& Herpers, 1994). Regarding police officers, McCaslin et al. (2006a) concluded that the greater the personal threat during a critical incident, the greater risk the risk to a police officer of subsequent distress. In another cross-sectional study, Robinson and colleagues (1997) found that experiences of situational threat were significantly associated with somatization.

However, MHPs after such incidents are multifactorally determined and follow a complex process. With respect to other determinants of MHPs, studies have shown that previous or pre-event MHPs and organizational stressors play an important role. Pre-event MHP findings indicate that previous MHPs are important predictors of postevent MHPs. For instance, after the Oklahoma bombing North and colleagues (2002) found that the rate of postevent nonalcohol disorders among firefighters was four times higher in those with predisaster psychopathology (43 vs. 11\%). Another study, also using retrospectively collected data on pre-event mental health, reported similar findings (Alvarez \& Hunt, 2005). After the 9/11 terrorist attacks, deployed canine and rescue handlers with a history of mental illness compared to colleagues without such a history reported more symptoms of depression, psychological distress, and more often met criteria for current disorder.

The very few longitudinal studies among police officers on critical incidents and MHPs, suggest that preevent MHPs tend to be even better predictors of current MHPs than exposure to critical incidents.

For example, in a study among junior officers (Hodgins, Creamer, \& Bell, 2001), MHP at baseline and critical incident exposure were both (modestly) predictive for PTSD at follow-up 12 months later. However, critical incidents were not independent predictors of MHPs at follow-up in contrast to MHPs at baseline. In McCaslin et al.'s study (McCaslin et al., 2006b) the variance of post-9/11 PTSD scores explained by pre-9/11 PTSD scores was much higher than the variance explained by $9 / 11$ exposure scores (based on intercorrelations: 38 vs. 17\%). In other analyses disaster-exposure has not been significant, in contrast to pre-event PTSD scores. Alexander and Wells (1991) found no significant change in individual prepost disaster depression scores among officers, indicating that previous depression symptoms were a strong predictor. However, in the study of Meffert et al. (2008) among police recruits, exposure to critical incidents in the past 12 months was stronger, although modest, related to PTSD symptomatology at followup 1 year after baseline $(r=.28)$, than trait anger at baseline $(r=.19)$.

With respect to organizational stressors, Brown et al. (1999) concluded 10 years ago that much of the research among police officers showed that organizational and management stressors were more likely sources of adverse psychological reactions than operational stressors. For example, the results of Violanti related to PTSD symptomatology and Aron's (1993) cross-sectional study demonstrate that organizational stressors had a total effect on distress $\sim 6.3$ times greater than that of operational stressors. Similar findings were reported by Hart et al. (1995); they concluded that organizational stressors were more important than operational experiences in determining psychological distress and well-being. More recently, Huddleston et al. (2007) found that among police recruits these stressors were, like MHPs at baseline, modest but significant independent predictors for MHPs 1 year later, while traumatic events were not.

Traumatic events were modestly predictive of intrusions and avoidance reactions at follow-up, but interestingly organizational stressors were stronger predictors. In the cross-sectional study of Berg et al. (2006), the frequency of job pressure and lack of support was associated with more subjective health problems and anxiety symptoms than were serious operational tasks and work injuries. In Collins and Gibbs' (2003) cross-sectional study, verbal and physical aggression was, on a bivariate level, positively associated with psychological distress (GHQ "caseness"). However, further analyses showed that 
Velden, P.G. van der, Kleber, R.J., Grievink, L., Yzermans, J.C. Confrontations with aggression and mental health problems in police officers: the role of organizational stressors, life-events and previous mental-heol th problems. Psychological Trauma: Theory, Research, Practice, and Policy: 2010, 2(2), 135-144

occupational stressors ranking most highly within the population were not specific to policing, but rather to organizational issues such as the demands of work impinging upon home life, lack of consultation and communication, lack of control over workload, inadequate support, and excess workload in general. The cross-sectional study of Liberman et al.(2002) among officers showed that routine stressors predicted psychological distress as well as PTSD symptomatology, but found that the predictive values were independent of and larger than the predictive value of critical incidents exposure.

Moreover, with respect to stressors normal life-events such as divorce or burglary may also influence MHPs (cf. Brewin, Scragg, Robertson, Thompson, d'Ardenne, \& Ehlers, 2000; Ozer, Best, Lipsey, \& Weiss, 2003). For example, Hartley et al. (2007) found a J-shaped association between negative life-events and depression symptoms, but did not find an association between traumatic police incidents and depression.

These findings strongly suggest that police mental health programs should not focus exclusively on eventrelated interventions since previous MHPs and organizational stressors play an important role. However, although problems caused by confrontations with aggression have been mentioned in older literature (cf.

Cullen, Link, Travis, \& Lemming, 1983; Perrier \& Toner, 1984), to the best of our knowledge no previous studies among police officers have been published in scientific journals that exclusively focus on these four variables (i.e., frequency of aggression incidents, previous MHPs, life-events, and organizational stressors).

To fill this gap and provide relevant information for police mental health care programs, we have analyzed data of a longitudinal study among police officers. Our first research question is: to what extent does the frequency of confrontations with aggression incidents compared to organizational stressors and previous mental health problems predict current mental health problems among officers while taking into account relevant variables that may confound associations such as life-events, gender, age, and education level? We further controlled for smoking because smoking may increase the risk for mental health problems (cf. Feldner, Babson, \& Zvolensky, 2007; Klungsøyr, Nygård, Sørensen, \& Sandanger, 2006; Koenen et al., 2005; van der Velden et al., 2007; van der Velden, Kleber, \& Koenen, 2008). Based on previous results, we hypothesized that: (a) The association between the frequency of confrontations with aggression incidents and MHPs is no longer a significant predictor when organizational stressors are taken into account, (b) Organizational stressors and life-events remain significant predictors when previous MHPs are taken into account, and (c) Previous MHPs are the most powerful predictors.

In addition, current studies do not examine these associations among officers with and among officers without previous MHPs.

Therefore, it is unclear whether officers without previous MHPs react differently to frequent aggression incidents, organizational stressors, and life-events than do their colleagues with previous MHPs. The second research question, therefore, is whether these associations differ between these two sub groups. We hypnotized that: officers with previous MHPs are more vulnerable to developing chronic MHPs because of these stressors than are officers without previous MHPs to developing new MHPs.

To make the distinction between officers with and without MHPs in the present study we examined several relevant mental health problems such as severe anxiety, depression, hostility and burnout symptoms, and severe sleeping problems.

\section{METHOD.}

\section{Background, Procedures, and Participants.}

For the present study, data from a three-wave longitudinal study following a fireworks disaster in the Netherlands were used. This disaster took place in the eastern part of the Netherlands in May, 2000. Details on study design and measures have been published previously and are briefly described here (van Kamp et al., 2006; van der Velden et al., 2006; van der Velden et al., 2008; for a comprehensive overview see: van der Velden, Yzermans, \& Grievink, 2009). The Medical Ethical Testing Committee approved the study protocols and respondents gave their informed consent. Officers involved in this disaster participated in postevent surveys at 2-3 weeks, 18 months, and almost 4 years.

The reason why we used this longitudinal dataset to address our research question needs some explanation. In this study we used the data of the second and third surveys because a previous study (Grievink et al., 2002) demonstrated that very few of the officers suffered from disaster-related posttraumatic stress symptoms at the second survey. Compared to a control group of police, involved officers showed minimal or no differences in mental health problems at 18 months (Grievink et al., 2002; in 
Velden, P.G. van der, Kleber, R.J., Grievink, L., Yzermans, J.C. Confrontations with aggression and mental health problems in police officers: the role of organizational stressors, life-events and previous mental-heoflth problems. Psychological Trauma: Theory, Research, Practice, and Policy: 2010, 2(2), 135-144

fact, this was the rationale for not including the control group of officers in the last survey 4 years postdisaster). Another prospective study among rescue workers (including police) and uninvolved controls, using electronic medical records, demonstrated similar findings. Immediate increases were found in the first year postdisaster for psychological problems. Rates of sick leave for psychological problems returned to predisaster levels after 1 year (Morren, Dirkzwager, Kessels, \& Yzermans, 2007).

Since the disaster did not play a (major) role in mental health problems 18 months postdisaster, it gave us a unique opportunity to consider the second survey as a baseline measure (T0) and the third as a follow-up (T1). The responses at $\mathrm{T} 0$ and $\mathrm{T} 1$ were 79.5 and $80.5 \%$, respectively. To minimize confusion introduced by disaster-related mental health problems, we decided to exclude the following respondents: (a) those who at the second survey still reported high levels of disaster-related intrusion and avoidance reactions according to the Impact of Event Scale (IES $>25, n=6$; Horowitz et al., 1979; van der Ploeg, Mooren, Kleber, van der Velden, \& Brom, 2004); (b) those who met the criteria of PTSD according to the Self Report Scale for PTSD (SRS-PTSD, $n=2$; Carlier, Lamberts, van Uchelen, \& Gersons, 1998) and finally; (c) those who left the police organization $(n=5)$; and/or respondents with incomplete data on these three variables $(n=25)$. The total study sample comprised 473 officers.

\section{MATERIALS.}

Participants were asked to fill out a number of "paper-andpencil" questionnaires. Demographic information concerning gender, age and level of education was obtained at both surveys.

\section{Aggression and life-events.}

Confrontations with aggression during work, were examined at T1 through two questions taken from the Acute Stress List (van der Velden \& Kleber, 1994), with 7-point Likert scales: "How often in the past 12 months have you been confronted with people who used physical aggression against you?", and "who seriously threatened you (without using physical aggression against you)?" $(1=$ not in past year, $7=$ once or more every day). In addition, 19 life-events in the 12 months before T1 were examined, events such as death or serious illness of a significant other, burglary, traffic accidents, and divorce. For the present study scores were dichotomized (confronted with one or more life-events: $1=$ no, $2=$ yes).

MHPs.

The Symptom Checklist 90-R (SCL-90-R, Derogatis, 1977) was administered to examine severe anxiety, depression, and hostility symptoms, and sleeping problems. The validity and reliability of the Dutch SCL90-R has proven to be satisfactory (Arrindell \& Ettema, 1986). Items have a 5-point Likert scale ( $1=$ not at all, $5=$ extremely) and assessed several symptoms over the preceding 7 days. The Dutch norm tables for men and women (Arrindell \& Ettema, 1986) were used to identify respondents with severe symptoms, that is, with high or very high scores (men: anxiety $\geq 15$, depression $\geq 23$, hostility $\geq 8$, sleeping problems $\geq 6$; women: anxiety $\geq 18$, depression $\geq 28$, hostility $\geq 9$, sleeping problems $\geq 7$ ). To examine burnout symptoms we administered the 8-item subscale emotional exhaustion of the Maslach Burnout Inventory (MBI; Maslach \& Jackson, 1986), with 6-point Likert scales $(0=$ never, $6=$ always). Respondents with high or very high scores (score $\geq 2.50$; Schaufeli \& van Dierendonck, 1994; all $\alpha \mathrm{s} \geq 0.91$ ) were considered to have severe symptoms of burnout.

Smoking.

To examine current smoking (cigarettes, pipe, cigars) at T1, standardized smoking questions of the Dutch Local and National Public Health Monitor (GGD, 2003) were applied (Do you ever smoke?; 1= yes, 2 = no, but did in the past; $3=$ no, I never smoked). For the present study smoking was dichotomized (current smoking, $1=$ no, 2 = yes).

Organizational stressors.

To gain insight into organizational stressors, we examined problems in relationships with colleagues and superiors at work (such as conflicts, lack of support in case of problems, negative atmosphere, and absence of appreciation). For this purpose the Dutch VBBA (van Veldhoven, Meijman, Broersen, \& Fortuin, 1997, 2002) was administered at T1. The two subscales with respect to relationships at work consist of nine items with Likert scales $(0=$ always, $3=$ never; all $\alpha$ s $>0.91)$.

Items of the subscales are positively or negatively formulated.Higher sum scores reflect more problems. For the present study a distinction was made between low levels (colleagues: scores $\leq 3$; superiors: scores 
Velden, P.G. van der, Kleber, R.J., Grievink, L., Yzermans, J.C. Confrontations with aggression and mental health problems in police officers: the role of organizational stressors, life-events and previous mental-heaft problems. Psychological Trauma: Theory, Research, Practice, and Policy: 2010, 2(2), 135-144

$\leq 3$ ), medium levels (colleagues: $3<$ scores $\leq 6$; superiors $3<$ scores $\leq 7$ ), and high levels of organizational stressors (colleagues: scores $>6$; superiors: scores $>7$ ).

\section{[TABLE 1].}

\section{Data Analyses.}

To be able to make a reliable distinction between officers with and without MHPs, respondents were considered to have a MHP when they reported severe symptoms on one or more sub scales of the SCl-90-R and/or the MBI. Thus, when officers had high scores on at least one sub scale, they were considered to have MHPs while officers who did not have scores on any of the sub scales were considered not to have MHPs. For both types of aggression we distinguished three sub groups according to the frequency of confrontations: (a) Not in past 12 months, (b) Sometime in past 12 months (once or more in every 6 months to once or more in past 12 months), and (c) Often in past 12 months (once or more every day to once or more every 3 months). Logistic regression analyses were conducted to examine the bivariate associations between predictors (aggression incidents, organizational stressors, life events, and MHPs at baseline) and MHPs at follow-up, by means of odd ratios. Stepwise logistic analyses were carried out to assess the independent association between confrontations with aggression, organizational stressors, life-events and MHPs at T0, and MHPs at T1. At Step 1, confrontations with aggression and organizational stress were entered. At Step 2, life-events were added and at Step 3 MHPs at baseline were added. Thus, in the last analyses all predictors were entered in addition to age, sex, and educational level. These stepwise logistic regression analyses were repeated separately among respondents with and without MHPs at baseline (MHPs as predictors were excluded). In these analyses, at the final step (Step 2) life-events were added in addition to age, sex, and educational level.

\section{RESULTS}

\section{Demographic Characteristics, Smoking, Mental Health Problems, and Confrontations With Aggression}

The mean age of the respondents was 39.8 years $(S D=7.5)$, and $12.7 \%$ were female. With respect to educational level, $27.3 \%$ had junior high/middle school level, $62.6 \%$ had high school level, and $9.1 \%$ had college degree/university level. Approximately one in five was a current smoker (19.2\%). The total proportion of respondents with MHPs at baseline $(\mathrm{T} 0=18.0 \%$; anxiety $=2.6 \%$, depression $=4.5 \%$, hostility $=5.8 \%$, sleeping problems $=10.1 \%$, and burnout $=6.6 \%)$ and follow-up was equal $(\mathrm{T} 1=17.4 \%$; anxiety $=3.6 \%$, depression $=5.4 \%$, hostility $=6.8 \%$, sleeping problems $=9.2 \%$, and burnout $=7.7 \%$ ). More than half (54.5\%) of those with MHPs at T1, reported MHPs at T0. As expected, those frequently confronted with physical aggression were more likely to be frequently confronted with serious threat during work or vice versa $(r=.75, p=.00)$. To prevent multicollinearity, we analyzed the described associations for serious threat and physical aggression separately.

\section{Confrontations With Serious Threat, Organizational Stressors, Life-Events, and MHPs at Baseline as Predictors of MHPs at Follow-Up}

Table 1 shows that among the total group of respondents, there was a statistical trend $(0.05 \leq p<.10)$ that officers who were often seriously threatened were more likely to have MHPs at follow-up than colleagues without these experiences. On a bivariate level, the two organizational stressors, life-events and MHPs at baseline were all significant and positively associated with MHPs at follow-up. Serious threat was no longer significant when organizational stressors and/or and life-events were entered into the model (Steps 1 and 2). The full multivariate model (Step 3) shows that problems with colleagues, life-events, and MHPs, statistically significantly predicted MHPs at follow-up, while MHPs at baseline were the most powerful predictors.

Among officers without MHPs at baseline, those who were often seriously threatened were more likely to have MHPs at follow-up (see Table 2). However, when organizational stressors and/or life-events were taken into account (Steps 1 and 2), serious threat was no longer significant. In the full model (Step 2) only problems with colleagues were statistically significantly associated with MHPs at follow-up.

These analyses were repeated among the smaller group of officers with MHPs at baseline $(n=80$, data not shown in table). 
Velden, P.G. van der, Kleber, R.J., Grievink, L., Yzermans, J.C. Confrontations with aggression and mental health problems in police officers: the role of organizational stressors, life-events and previous mental-healt problems. Psychological Trauma: Theory, Research, Practice, and Policy: 2010, 2(2), 135-144

Only at Step 1 was there a statistical trend that officers with high levels of physical aggression were more likely to have to have MHPs at follow-up (Adjusted odds ratio $[\mathrm{OR}]=3.60, p=.083,95 \%$ confidence interval $[\mathrm{CI}]=0.85-15.26)$. On a bivariate level, only problems with superiors $(\mathrm{OR}=3.84, p=.031,95 \%$ $\mathrm{CI}=1.13-13.07)$ and life-events $(\mathrm{OR}=3.90, p=.004,95 \% \mathrm{CI}=1.54-9.89)$ were statistically significantly associated with MHPs at follow-up. There was a statistical trend that problems with colleagues were associated with MHPs at $\mathrm{T} 1(\mathrm{OR}=3.50, p=.056,95 \% \mathrm{CI}=0.98-12.67)$. In contrast to officers without MHPs at baseline, life-events were independently associated with MHPs at follow-up (Step 2: Adjusted OR $=3.93, p=.016,95 \% \mathrm{CI}=1.29-11.95)$ and there was a statistical trend that problems with colleagues were associated with MHPs at follow-up (Step 2: Adjusted OR $=6.01, p=.056,95 \% \mathrm{CI}=0.95-37.82$ ). Thus, officers confronting life-events and, to a lesser extent, who had problems with colleagues were more likely to have chronic MHPs.

\section{Confrontations With Physical Aggression, Organizational Stressors, Life-Events, and MHPs at Baseline as Predictors of MHPs at Follow-Up}

The results of the logistic aggression analyses with confrontations with physical aggression as predictor are presented in Table 3 (total group of officers) and Table 4 (officers without MHPs at baseline). Table 3 shows that physical aggression is not (independently) associated with MHPs at follow-up. As expected, officers with severe problems with colleagues, officers who were confronted with life-events, and officers with MHPs at baseline were more at risk for MHPs at follow-up than those without these experiences or problems (see Step 3). The outcomes of the analyses among officers without MHPs at baseline (see Table 4), shows that only problems with colleagues were independently associated with MHPs at follow-up (Step 2 , Adjusted $\mathrm{OR}=4.78, p=.01$ ). Similar analyses among those with MHPs at baseline (data not shown in table) showed that, again, problems with colleagues (Adjusted $\mathrm{OR}=6.56, p=.05,95 \% \mathrm{CI}=0.98-43.87$ ) and life-events (Step 2, Adjusted $\mathrm{OR}=3.78, p=.02,95 \% \mathrm{CI}=1.23-11.59$ ) were independently associated with MHPs at followup.

Additional analyses among the total sample showed that officers who were often seriously threatened and were often physically attacked $(n=115)$, were not more at risk for MHPs at follow-up than colleagues without $(n=83)$ these experiences $(\mathrm{OR}=1.57, p=.23,95 \% \mathrm{CI}=0.75-3.28$; Step 3, Adjusted OR $=2.22$, $p=.15,95 \% \mathrm{CI}=0.076-6.48$ ). However, problems with colleagues (Step 3, Adjusted OR $=9.09, p=.007$, $95 \% \mathrm{CI}=1.85-44.64$ ) and MHPs at baseline (Step 3 Adjusted OR $=12.60, p=.00,95 \% \mathrm{CI}=4.29-$ 36.97) were independently associated with MHPs at follow-up.

\section{[TABLE 2 AND TABLE 3].}

In the present study we excluded the very small group of officers with disaster-related posttraumatic stress symptoms according to the SRS-PTSD and IES, and those with incomplete data. In addition, previous studies showed that 1.5 years postevent, when compared to a control group of police, involved officers showed minimal or no differences in mental health problems.

However, despite this selection and previous findings it is possible, in principle, that the results in the current study are confounded by the disaster experiences. For this reason we repeated the multivariate logistic regression analyses and added disaster exposure (the sum of 21 disaster experiences that officers had seen, felt or heard, $M=4.10, S D=4.83$ ) as predictor in the full models (Step 3 in analyses with MHPs at baseline as predictor; Step 2 in analyses without MHPs at baseline as predictor). As expected, adding exposure as a predictor did not affect our results: adjusted ORs and $p$ values of all other predictors were similar or almost similar. The (nonsignificant) adjusted ORs for exposure in these analyses were less than 1.064

\section{DisCUSSION.}

To the best of our knowledge this is the first longitudinal study among police officers that examines the independent predictive values of frequent confrontations with aggression incidents in the preceding 12 months, organizational stressors, life-events, and nonretrospectively collected data on previous MHPs, for current MHPs.

In accordance with the studies of McCaslin et al. (2006) and Robinson et al. (1997), frequent serious threat was statistically significantly associated with MHPs at follow-up among officers without MHPs at baseline. However, these incidents were not associated with MHPs at follow-up among officers with MHPs at 
Velden, P.G. van der, Kleber, R.J., Grievink, L., Yzermans, J.C. Confrontations with aggression and mental health problems in police officers: the role of organizational stressors, life-events and previous mental-heof th problems. Psychological Trauma: Theory, Research, Practice, and Policy: 2010, 2(2), 135-144

baseline. This may explain why, with respect to the association between serious threat and MHPs at followup, we found a statistical trend among the total study sample $(p=.06)$. Interestingly, life-events contributed to ongoing MHPs among officers with MHPs at baseline, but not to the development of new MHPs among those without MHPs at baseline. Thus, officers with previous MHPs appear to be less resilient to the possible negative effects of life-events than colleagues without previous MHPs.

Remarkably, they do not appear to be any less resilient to the possible adverse effects of aggression.

However, in line with previous research, the associations between serious threat and MHPs at follow-up were no longer statistically significant when organizational stressors were taken into account (cf. Brown et al., 1999; Collins \& Gibbs, 2003; Huddleston et al., 2007; Violanti \& Aron, 1993; Hart et al., 1995).

In all analyses organizational stressors, that is, problems with colleagues, remained a significant predictor. Our results indicate that, in accordance with most previous longitudinal studies, previous MHPs were the most powerful predictors of MHPs at follow-up (cf. Alexander \& Wells, 1991; Alvarez \& Hunt, 2005; Hodgins et al., 2001; Huddleston et al., 2007; Murphy, Beaton, Pike \& Johnson, 1999; North et al., 2002).

\section{[TABLE 4].}

The frequency of confrontations with physical aggression was not associated with MHPs at follow-up in our study sample, and additional analyses showed that those who had often been physically attacked and often been seriously threatened were not more likely to have MHPs at follow-up than their colleagues without these experiences. This is in contrast with findings from two cross-sectional studies using the same questionnaire (Acute Stress List), concerning aggression toward employees of a psychiatric hospital and employees of a large public transport company in the Netherlands (van der Velden \& Herpers, 1994; van der Velden \& Kleber, 2002) where employees who were often seriously threatened and often confronted with physical aggression, had more MHPs than employees who had no experiences with these events in the preceding year.

Our findings regarding the total study sample more or less confirm our first set of hypotheses: only problems with superiors were, contrary to our expectations, not independently associated with MHPs at follow-up. With respect to our "vulnerability" hypothesis, officers with MHPs at baseline and confronted with life-events were indeed more likely to (also) have MHPs at followup, but organizational stressors (i.e., problems with colleagues) had similar independent predictive values for MHPs at follow-up as among officers without MHPs at baseline. Contrary to the "vulnerability" hypothesis, serious threat was on a bivariate level associated with MHPs at follow-up among respondents without MHPs at baseline, but not among respondents with MHPs at baseline.

How can this absence of independent associations between aggression and MHPs further be explained? Since the introduction of the Working Conditions Act in the Netherlands in 1994, employers are obliged to take care of employees affected by critical incidents to prevent as far as possible psychosocial stressors and stress (cf. van der Velden et al., 2006). Many police stations in the Netherlands have in-company victim assistance teams. Assuming that officers have benefited from this assistance, for instance because it provided social companionship that may protect against the development of MHP (cf. Carlier et al., 1997), this may explain why we found no independent relationships between aggression incidents and MHPs at follow-up. Perhaps the absence of victim assistance teams may have placed victimized officers at great risk for MHPs at follow-up. However, this explanation does not clarify why previous MHPs were dominant determinants. Referring officers with ongoing severe MHPs to mental health services is one of the tasks of victim assistance teams. On the other hand, offering help to reduce or solve organizational stressors, which are important determinants, is outside the area of these teams.

\section{Limitations and Future Research.}

Strengths of our study are its longitudinal nature, the large sample size, the nonretrospective collected data on previous MHPs, and the ability to control for several relevant confounders.

Nevertheless, some limitations should be noted. To prevent recall bias as much as possible, we focused on the previous year (like many other studies) and did not examine aggression incidents across the total period of 27 months between T0 and T1. In addition, the results are based on a sample of officers that were involved in rescue and surveillance activities following a disaster that took place in the eastern part of the Netherlands, and not on a national sample. However, a national study in 2005 among officers in the Netherlands $(N=1214)$ showed that a similar large group, based on a postal code matched sub group of 
Velden, P.G. van der, Kleber, R.J., Grievink, L., Yzermans, J.C. Confrontations with aggression and mental health problems in police officers: the role of organizational stressors, life-events and previous mental-healt problems. Psychological Trauma: Theory, Research, Practice, and Policy: 2010, 2(2), 135-144

executive officers, was confronted with physical aggression during work (once or more: 73 vs. $74 \%$ in our study; BZK, 2006).

We were not able to control for all other potential confounders, such as confrontations with child abuse, death of a colleague and self coping efficacy (cf. Luszczynska, Benight, \& Cieslak, 2009).

We did not examine years of service of the respondents within the police force, but we expect that among police officers age and years of service are highly correlated. Although previous studies had shown that a disaster does not play a (major) role, we excluded a small sub group of officers with specific disasterrelated PTSD (symptomatology) at baseline to minimize confounding by disaster-related mental health problems. Nevertheless, in principle it is possible that some officers suffered from, for instance, anxiety symptoms because of this event. However, it is highly unlikely that among the sub group without MHPs at baseline (i.e., no high scores on any of the sub scales) some went on to suffer from this event 18 months postevent. Moreover, additional analyses with disaster exposure did not affect our findings.

Although the examined MHPs are common and relevant posttraumatic stress reactions, we did not assess specific event-related intrusions and avoidance reactions. For example, we assessed self-reported sleeping problems in general, but not sleeping problems as a symptom of intrusions. However, Huddleston et al.

(2007) found that organizational stressors were stronger predictors of intrusions and avoidance reactions at follow-up than traumatic events. Moreover, the prevalence of MHPs after critical incidents tends to be higher than the prevalence of PTSD (cf. Rona, Hooper, Jones, Iversen, Hull, Murphy, Hotopf, \& Wessely, 2009). Future multiwave studies ought to examine the possible (independent) cumulative effects of an accumulation of aggression incidents over a substantial longer period.

\section{Conclusions and Practical Implications.}

Our outcomes in combination with the findings of previous studies are important for the psychosocial care of police officers.

The fact that in our Study 55\% of those with MHPs at follow-up already had MHPs at baseline clearly suggests that MHPs in this sub group were more or less chronic. The chronic character of MHPs in this large sub group raises serious questions related to the use of trauma counseling, in particular single session interventions.

There is serious debate about the use of such interventions first because there is no evidence from RCT studies that they prevent posttraumatic stress reactions such as PTSD and some studies have even showed opposite effects (cf. ACPMH, 2007; Chemtob, Tomas, Law, \& Cremniter, 1997; van Emmerik, Kamphuis, Hulsbosch, \& Emmelkamp, 2002) and second, research methodologies and examined outcomes in studies on such postevent interventions have been questioned (Deahl, Srinivasan, Jones, Neblett \& Jolly, 2001).

Our results also give force to the important theoretical question of why a positive effect (decreasing the risk of postincident MHPs) of single session psychological debriefing should be expected among those with chronic MHPs. This question is especially relevant because our empirical findings showed that these cases are common (55\%; cf. Rona et al., 2009), which is supported by our practical experience at the Dutch Institute for Psychotrauma with officers and other victims of aggression. In cases where victims suffer from ongoing MHPs in the weeks after the event, a variable majority already suffered from MHPs in the period because of the event. Consequently, future studies on the effects of single session debriefing and other preventive interventions among affected officers should take previous MHPs into account.

In any event, our results suggest that when officers report MHPs after aggression incidents, possible previous MHPs should definitely be assessed and examined as part of a mental health program.

In these cases (where MHPs are more or less chronic), referral to relevant counseling or treatment should be offered (Bisson, Brayne, Ochberg, \& Everly, 2007; Kleber \& van der Velden, 2009). Therefore, in our opinion, chronic MHPs should be considered a contra-indication for single session interventions after such events. In addition, our findings suggest that we ought to be very careful, when officers report MHPs after a single aggression incident, not to automatically attribute MHPs solely to this single aggression incident.

The question remains regarding which interventions might be effective to reduce MHPs. Trauma studies on interventions aimed at reducing or preventing the risk of ongoing MHPs tend to be predominantly focused on possible interventions after the event, such as postevent psychological first aid and psychoeducation (Everly, Phillips, Kane, \& Feldman, 2006; Verbern et al., 2007), and early screening to identify those at risk of postevent MHPs and subsequent early treatment (O'Donnell, Bryant, Creamer, \& Carty, 2008). Without ignoring the relevancy of such postevent interventions for officers (cf. Boscarino, Adams, Foa, \& Landrigan, 2006; Brewin, Scragg, Robertson, Thompson, d'Ardenne, \& Ehlers, 2008), our and 
Velden, P.G. van der, Kleber, R.J., Grievink, L., Yzermans, J.C. Confrontations with aggression and mental health problems in police officers: the role of organizational stressors, life-events and previous mental-heol th problems. Psychological Trauma: Theory, Research, Practice, and Policy: 2010, 2(2), 135-144

others' findings denote the necessity for attention to be paid by the management toward mental health and organizational stressors, life-events, and subsequent relevant support and interventions not only after potential traumatic events at work but regularly. Accordingly, an integrated mental health program covering organizational as well as operational stressors and normal life-events, including regular screening for MHPs, appears to be more appropriate (cf. Alvarez \& Hunt, 2005; Hartley et al., 2007; Huddleston et al., 2007; Kleber \& van der Velden, 2009; van der Ploeg \& Kleber, 2003; Violanti \& Aron, 1993). Although a recent systematic review (Pen alba, McGuire, \& Leite, 2009) concluded that there is critical lack of statistically powered studies of psychosocial interventions among police officers, this policy could be an effective way to reduce the risk of MHPs among police officers.

\section{REFERENCES.}

ACPMH. (2007). Australian guidelines for the treatment of adults with acute stress disorder and posttraumatic stress disorder. Melbourne, ACPMH.

Agolla, J. E. (2009). Occupational stress among police officers: The case of Botswana police service.

Research Journal of Business Management, 2, 25-35.

Alexander, D. A., \& Wells, A. (1991). Reactions of police officers to body handling after a major disaster: A before and after comparison. British Journal of Psychiatry, 159, 547-555.

Alvarez, J., \& Hunt, M. (2005). Risk and resilience in canine search and rescue handlers after 9/11. Journal of Traumatic Stress, 18, 497-505.

Andrew, M. E., McCanlies, E. C., Burchfiel, C. M., Charles, L. E., Hartley, T. A., Fekedulegn, D., \& Violanti, J. M. (2008). Hardiness and psychological distress in a cohort of police officers. International Journal of Emergency Mental Health, 10, 137-147.

Arrindell, W. A., \& Ettema, J. H. M. (1986). Handleiding bij een multi- dimensionele psychopathologieindicator SCL-90 [Manual for a Multidimensional Psychopathology Indicator SCL-90]. Lisse, The Netherlands: Swets \& Zeitlinger/Swets Test Publishers.

Berg, A. M., Hem, E., Lau, B., \& Ekeberg Ø. (2006). An exploration of job stress and health in the Norwegian police service: A cross sectional study. Journal of Occupational Medicine and Toxicology, 1, 26.

Bisson, J. I., Brayne, M., Ochberg, F. M., \& Everly, G. S., Jr. (2007). Early psychosocial intervention following traumatic events. American Journal of Psychiatry, 164, 1016-1019.

Boscarino, J. A., Adams, R. E., Foa, E. B., \& Landrigan, P. J. (2006). A propensity score analysis of brief worksite crisis interventions after the World Trade Center disaster: Implications for intervention and research. Medical Care, 44, 454-462.

Brewin, C. R., Andrews, A., \& Valentine, J. D. (2000). Meta-analysis or riks factors for posttraumatic stress disorder in trauma-exposed adults. Journal of Clinical and Consulting Psychology, 68, 748-766.

Brewin, C. R., Scragg, P., Robertson, M., Thompson, M., d'Ardenne, P., \& Ehlers, A. (2008). Promoting mental health following the London bombings: A screen and treat approach. Journal of Traumatic Stress, 21, 3-8.

Brown, J., Fielding, J., \& Grover, J. (1999). Distinguishing traumatic, vicarious and routine operational stressor exposure and attendant adverse consequence in a sample of police officers. Work \& Stress, 13, 312-325.

BZK. (2006). Personeels-en Mobiliteitsonderzoek (Employee and mobility research report). The Netherlands: Den Haag, Ministry of the Interior and Kingdom Relations.

Carlier, I. V. E., Lamberts, R. D., \& Gersons, B. P. R. (1997). Risk factors for posttraumatic stress symptomatology in police officers: A prospective analysis. Journal of Nervous and Mental Disease, 185, 498-506.

Carlier, I. V. E., Lamberts, R. D., van Uchelen, A. J., \& Gersons, B. P. R. (1998). Clinical utility of a brief diagnostic test for posttraumatic stress disorder. Psychosomatic Medicine, 60, 42-47.

Chemtob, C. M., Tomas, S., Law, W., \& Cremniter, D. (1997). Postdisaster psychosocial intervention: A field study of the impact of debriefing on psychological distress. American Journal of Psychiatry, 154, 415-417.

Collins, P. A., \& Gibbs, A. C. C. (2003). Stress in police officers: A study of the origins, prevalence and severity of stress-related symptoms within a county police force. Occupational Medicine, 53, 256-264.

Cullen, F. T., Link, B. G., Travis, L. F., \& Lemming, T. (1983). Paradox in Policing - A Note on Perceptions of Danger. Journal of Police Science and Administration, 11, 457-462.

Deahl, M. P., Srinivasan, M., Jones, N., Neblett, C., \& Jolly, A. (2001). Evaluating psychological debriefing: Are we measuring the right outcomes? Journal of Traumatic Stress, 14, 527-529. 
Velden, P.G. van der, Kleber, R.J., Grievink, L., Yzermans, J.C. Confrontations with aggression and mental health problems in police officers: the role of organizational stressors, life-events and previous mental-healt problems. Psychological Trauma: Theory, Research, Practice, and Policy: 2010, 2(2), 135-144

Derogatis, L. R. (1983). SCL-90-R Administration, Scoring, Procedures Manual-II for the (revised) version and other instruments of the psychopathology rating scale series. Towson, MD: Clinical Psychometric Research.

Emmerik, A. A. van, Kamphuis, J. H., Hulsbosch, A. M., \& Emmelkamp, P. M. (2002). Single session debriefing after psychological trauma: A meta-analysis. Lancet, 360, 766-671.

Everly, G. S., Phillips, S. B., Kane, D., \& Feldman, D. (2006). Introduction to and overview of group psychological first aid. Brief Treatment and Crisis Intervention, 6, 130-136.

Evers, W., Tomic, W., \& Brouwers, A. (2002). Aggressive behaviour and burnout among staff of homes for the elderly. International Journal of Mental Health Nursing, 11, 2-9.

Feldner, M. T., Babson, K. A., \& Zvolensky, M. J. (2007). Smoking, traumatic event exposure, and posttraumatic stress: A critical review of the empirical literature. Clinical Psychology Review, 27, 4-45.

GGD Nederland (Health Authority Netherlands). (2003). Standaard vraagstelling roken (standardized questions for smoking). Utrecht, The Netherlands: GGD Nederland.

Grievink, L., Velden, P. G. van der, Christiaanse, B., Dijkema, M. B. A., Dusseldorp, A., Stellato, R. K., Dorresteijn, A. M. (2002). Gezondheid reddingswerkers Vuurwerkramp Enschede: Addendum bij rapportage gezondheidsonderzoek 18 maanden na de ramp [Health problems rescue workers Fire Disaster Enschede, addendum report healths problems victims 18 month post-disaster]. Zaltbommel, The Netherlands: Institute for Psychotrauma (IVP)/ Bilthoven; National Institute of Public Healh and Environment (RIVM).

Hart, P. M., Wearing, A. J., \& Headey, B. (1995). Police stress and well-being: Integrating personality, coping and daily work experiences. Journal of Occupational and Organizational Psychology, 68, $133-165$.

Hartley, T. A., Violanti, J. M., Fekedulegn, D., Andrew, M. E., \& Burchfiel, C. M. (2007). Associations between major life events, traumatic incidents, and depression among Buffalo police officers. International Journal of Emergency Mental Health, 9, 25-35.

Hodgins, G. A., Creamer, M., \& Bell, R. (2001). Risk factors for posttrauma reactions in police officers: A longitudinal study. Journal of Nervous and Mental Disease, 189, 541-547.

Horowitz, M. J., Wilner, N., \& Alvarez, W. (1979). Impact of Event Scale: A measure of subjective stress. Psychosomatic Medicine, 41, 209-218.

Huddleston, L., Stephens, C., \& Paton, D. (2007). An evaluation of traumatic and organizational experiences on the psychological health of New Zealand police recruits. Work, 28, 199-207.

Jordan, B. K., Marmar, C. R., Fairbank, J. A., Schlenger, W. E., Kulka, R. A., Hough, R. L., \& Weiss, D. S. (1992). Problems in families of male Vietnam veterans with posttraumatic stress disorder. Journal of Consulting and Clinical Psychology, 60, 916-926.

Kamp, I. van, Velden, P. G. van der, Stellato, R., Roorda, J., Loon, J. van, Kleber, R. J., ... Lebret, E. (2006). Physical and mental health shortly after a disaster: First results from the Enschede firework disaster study. European Journal of Public Health, 16, 252-258.

Kessler, R. C., Sonnega, A., Bromet, E., Hughes, M., \& Nelson, C. B. (1995). Posttraumatic stress disorder in the National Comorbidity Survey. Archives of General Psychiatry, 52, 1048-1060.

Kleber, R. J., \& Velden P. G. van der (2009, in press). Acute stress at work. In J. Quick, M. J. Schabracq, \& C. L. Cooper (Eds.), Work and health psychology handbook (3rd ed., pp. 269-291). Chichester, England: Wiley/Blackwell.

Klungsøyr, O., Nygård, J. F., Sørensen, T., \& Sandanger, I. (2006). Cigarette smoking and the incidence of first depressive episode: An 11-year population-based follow-up study. American Journal of Epidemiology, 163, 421-432.

Koenen, K. C., Hitsman, B., Lyons, M. J., Niaura, R., McCaffery, J., Goldberg, J., . . Tsuang, M. (2005). A twin registry study of the relationship between nicotine dependence and posttraumatic stress disorder. Archives of General Psychiatry, 62, 1258-1265.

Kop, N., \& Euwema, M. C. (2001). Occupational stress and the use of force by Dutch police officers. Criminal Justice and Behavior, 28, 631-652.

Liberman, A. M., Best, S. R., Metzler, T. J., Fagan, J. A., Weiss, D. S., \& Marmar, C. R. (2002). Routine occupational stress and psychological distress in police. Policing: An International Journal of Police Strategies \& Management Volume, 25, 421-439.

Luszczynska, A., Benight, C. C., \& Cieslak, R. (2009). Self-efficacy and health-related outcomes of collective trauma: A systematic review. European Psychologist, 14, 49-60.

Maslach, C., \& Jackson, S. E. (1986). Maslach Burnout Inventory (2nd ed.). Palo Alto, CA: Consulting Psychologists Press.

McCaslin, S. E., Metzler, T. J., Best, S. R., Liberman, A., Weiss, D. S., Fagan, J., et al. (2006b). Alexithymia and PTSD symptoms in urban police officers: Cross-sectional and prospective findings. Journal of Traumatic Stress, 19, 361-373. 
Velden, P.G. van der, Kleber, R.J., Grievink, L., Yzermans, J.C. Confrontations with aggression and mental health problems in police officers: the role of organizational stressors, life-events and previous mental health problems. Psychological Trauma: Theory, Research, Practice, and Policy: 2010, 2(2), 135-144

McCaslin, S. E., Rogers, C. E., Metzler, T. J., Best, S. R., Weiss, D. S., Fagan, J. A., . . Marmar, C. R. (2006a). The impact of personal threat on police officers' responses to critical incident stressors. Journal of Nervous and Mental Disease, 194, 591-597.

Meffert, S. M., Metzler, T. J., Henn-Haase, C., McCaslin, S., Inslicht, S., Chemtob, C., \& Marmar, C. R. (2008). A prospective study of trait anger and PTSD symptoms in police. Journal of Traumatic Stress, 21, 410- 416.

Miller-Burke, J., Attridge, M., \& Fass, P. M. (1999). Impact of traumatic events and organizational response: A study of bank robberies. Occupational and Environmental Medicine, 41, 73-83.

Morren, M., Dirkzwager, A. J. E., Kessels, F. J. M., \& Yzermans, C. J. (2007). The influence of a disaster on the health of rescue workers: A longitudinal study. CMAJ, 176, 1279-1283.

Murphy, S. A., Beaton, R. D., Pike, K. C., \& Johnson, L. C. (1999). Occupational stressors, stress responses, and alcohol consumption among professional firefighters: A prospective, longitudinal analysis. International Journal of Stress Management, 6, 179-197.

North, C. S., Tivis, L., McMillen, C., Pfefferbaum, B., Cox, J., Spitznagel, E. L., . . Smith, E. M. (2002). Coping, functioning, and adjustment of

rescue workers after the Oklahoma City bombing. Journal of Traumatic Stress, 15, 171-175.

O'Donnell, M. L., Bryant, R. A., Creamer, M., \& Carty, J. (2008). Mental health following traumatic injury: Toward a health system model of early psychological intervention. Clinical Psychology Review, 28, 387406.

Ozer, E. J., Best, S. R., Lipsey, T. L., \& Weiss, D. S. (2003). Predictors of posttraumatic stress disorder and symptoms in adults: A meta-analysis. Psychological Bulletin, 129, 52-73.

Peñalba, V., McGuire, H., \& Leite, J. R. (2009). Psychosocial interventions for prevention of psychological disorders in law enforcement officers. Cochrane Database Systematic Reviews, 16, CD005601.

Perrier, D. C., \& Toner, R. (1984). Police stress: The hidden foe. Canadian Police College Journal, 8, 1526.

Ploeg, E. van der, Mooren, T. M., Kleber, R. J., Velden, P. G. van der, \& Brom, D. (2004). Construct validation of the Dutch version of the Impact of Event Scale. Psychological Assessment, 16, 16-26.

Ploeg, E. van der, \& Kleber, R. J. (2003). Acute and job stress stressors among ambulance personnel: Predictors of health problems. Occupational and Environmental Medicine, 60, 40-46.

Robinson, H. M., Sigman, M. R., \& Wilson, J. P. (1997). Duty-related stressors and PTSD symptoms in suburban police officers. Psychological Reports, 81, 835-845.

Rona, R. J., Hooper, R., Jones, M., Iversen, A. C., Hull, L., Murphy, D., . . . Wessely, S. (2009). The contribution of prior psychological symptoms and combat exposure to post Iraq deployment mental health in the UK military. Journal of Traumatic Stress, 22, 11-19.

Schaufeli, W., \& van Dierendonck, D. (1994). Burnout, een begrip gemeten: De Nederlandse versie van de Maslach Burnout Inventory (MBINL) [Burnout, the measurement of a construct. The Dutch version of the Maslach Burnout Inventory (MBI-NL)]. Gedrag \& Gezondheid, 22, 153-172.

Stephens, C., \& Miller, I. (1998). Traumatic experiences and posttraumatic stress disorder in the New Zealand police. Policing: International Journal of Police Strategies and Management, 21, 178-191.

Velden, P. G. van der, Grievink, L., Olff, M., Gersons, B. P. R., \& Kleber, R. J. (2007). Smoking as a risk factor for mental health disturbances after a disaster: A prospective comparative study. Journal of Clinical Psychiatry, 69, 87-92.

Velden, P. G. van der, Christiaanse, B., Kleber, R. J., Marcelissen, F. M. G., Dorresteijn, A. M., Drogendijk, A. N., . . . Meewisse, M. L. (2006). The effects of disaster exposure and post-disaster critical incidents on intrusions, avoidance and health problems among firefighters: A comparative study. Stress, Trauma and Crisis: An International Journal, 9, 73-93.

Velden, P. G. van der, Kleber, R. J., \& Koenen, K. C. (2008). Smoking predicts posttraumatic stress symptoms among rescue workers: A prospective study of ambulance personnel involved in the Enschede Fireworks Disaster. Drug and Alcohol Dependence, 94, 267-271.

Velden, P. G. van der, Yzermans, C. J., \& Grievink, L. (2009). The Enschede Fireworks Disaster. In Y. Neria, S. Galea, \& F. H. Norris (Eds.). Mental health and disasters (pp. 473-496). New York: Cambridge University Press.

Velden, P. G. van der, \& Herpers, T. M. M. (1994). Agressie in een psychiatrisch ziekenhuis [Aggression in a psychiatric hospital]. Gedrag \& Gezondheid, 5, 209-218.

Velden, P. G. van der, \& Kleber, R. J. (1994). Peilingslijst Acute Stress [Acute Stress List]. Utrecht, The Netherlands: Instituut voor Psychotrauma. Velden, P. G. van der, \& Kleber, R. J. (2002). Traumazorg in organisaties: Kader en praktijk [Trauma care in organisations: Background and practice]. In J. A. M. Winnubst, B. S. A. M. Holthuizen, M. Kiel, \& I. Weijman (Eds.), Praktijkboek gezond werken, Deel II (pp. 11.1-38). 
Velden, P.G. van der, Kleber, R.J., Grievink, L., Yzermans, J.C. Confrontations with aggression and mental health problems in police officers: the role of organizational stressors, life-events and previous mental healt problems. Psychological Trauma: Theory, Research, Practice, and Policy: 2010, 2(2), 135-144

Maarssen, The Netherlands: Elsevier Gezondheidszorg. Velden, P. G. van der, \& Kleber, R. J. (2009). Substance use and misuse after disasters. In Y. Neria, S. Galea, \& F. H. Norris (Eds.), Mental health and disasters (pp. 94-116). New York: Cambridge University Press.

Veldhoven, M. van, Meijman, T. F., Broersen, J. P. J., \& Fortuin, R. J. (1997). Handleiding VBBA. Onderzoek naar de beleving van psychosociale arbeidsbelasting en werkstress met behulp van de vragenlijst beleving en beoordeling van de arbeid (Manual VBBA, research on perceived psychosocial workstress with the Questionnaire on Experience and Assessment of Work. Amsterdam: Stichting Kwaliteitsbeoordeling Bedrijfsgezondszorg.

Veldhoven, M. van, Meijman, T. F., Broersen, S., \& Fortuin, R. J. (2002). Handleiding VBBA 2002 (2e editie; Manual VVBA). Amsterdam: Stichting Kwaliteitsbevordering Bedrijfsgezondheidszorg.

Vernberg, E. M., Steinberg, A. M., Jacobs, A. K., Brymer, M. J., Watson, P. J., Osofsky, J. D., . . Ruzek, J. I. (2007). Psychological first aid. Professional Psychology: Research and Practice, 39, 381-388.

Violanti, J. M., \& Aron, F. (1993). Sources of police stressors, job attitudes, and psychological distress. Psychological Reports, 72, 899-904.

\section{TABLES}

Table 1

Serious Threat and Other Predictors of Mental Health Problems at Follow-Up Among Total Sample of Police Officers

\begin{tabular}{|c|c|c|c|c|c|c|c|c|c|c|c|c|c|c|c|}
\hline & \multirow[b]{2}{*}{$N$} & \multirow[b]{2}{*}{$\%$} & \multirow{2}{*}{$\begin{array}{c}\% \text { MHP } \\
\text { at T1 }\end{array}$} & \multicolumn{3}{|c|}{ Bi-variate } & \multicolumn{3}{|c|}{ Step 1} & \multicolumn{3}{|c|}{ Step 2} & \multicolumn{3}{|c|}{ Step 3} \\
\hline & & & & OR & $p$ & $(95 \% \mathrm{CI})$ & Adj. OR & $p$ & $(95 \% \mathrm{CI})$ & Adj. OR & $p$ & $(95 \% \mathrm{CI})$ & Adj. $O^{a}$ & $p$ & $(95 \% \mathrm{CI})$ \\
\hline \multicolumn{16}{|c|}{ Being seriously threatened in 12 months before $\mathrm{T} 1$} \\
\hline Not (Ref.) & 118 & 26.3 & 12.7 & 1 & & & 1 & & & 1 & & & 1 & & \\
\hline Somet & 206 & 45.9 & 17.5 & 1.45 & 26 & $(0.76-2.79)$ & 1.38 & .35 & $(0.71-2.71)$ & 1.41 & .32 & $(0.72-2.77)$ & 1.56 & .28 & $(0.70-3.48)$ \\
\hline Often & 125 & 27.8 & 22.4 & 1.98 & .05 & $(1.00-3.93)$ & 1.81 & .11 & $(0.88-3.69)$ & 1.62 & .19 & $(0.79-3.35)$ & 2.07 & .10 & $(0.87-4.95)$ \\
\hline \multicolumn{16}{|c|}{ Level of organizational stressors: problems with colleagues } \\
\hline Low (Ref.) & 145 & 32.3 & 7.6 & 1 & & & 1 & & & 1 & & & 1 & & \\
\hline Mediu & 172 & 38.3 & 15.7 & 1.87 & .12 & $(0.85-4.09)$ & 1.89 & .11 & $(0.86-4.15)$ & 1.99 & .09 & $(0.90-4.41)$ & 1.84 & .18 & $(0.76-4.49)$ \\
\hline High & 132 & 29.4 & 31.1 & 3.91 & .00 & $(1.77-8.65)$ & 4.00 & .00 & $(1.80-8.86)$ & 4.12 & .00 & $(1.84-9.22)$ & 4.66 & .00 & $(1.85-11.77)$ \\
\hline \multicolumn{16}{|c|}{ Level of organizational stressors: problems with superiors } \\
\hline Low (Ref.) & 141 & 31.4 & 9.9 & 1 & & & 1 & & & 1 & & & 1 & & \\
\hline Medium & 161 & 35.9 & 14.3 & 1.51 & .25 & $(0.75-3.07)$ & 1.12 & .77 & $(0.53-2.37)$ & 1.14 & .74 & $(0.53-2.41)$ & 0.94 & .89 & $(0.41-2.20)$ \\
\hline High & 147 & 32.7 & 28.6 & 3.63 & .00 & $(1.88-7.01)$ & 1.93 & .08 & $(0.92-4.05)$ & 1.95 & .08 & $(0.92-4.12)$ & 1.75 & .20 & $(0.75-4.08)$ \\
\hline \multicolumn{16}{|c|}{ Life-events in 12 months before $\mathrm{T} 1$} \\
\hline No (Ref.) & 229 & 51 & 12.7 & 1 & & & & & & 1 & & & 1 & & \\
\hline Yes & 220 & 49 & 22.7 & 2.03 & .01 & $(1.23-3.35)$ & & & & 2.05 & .01 & $(1.21-3.48)$ & 2.26 & .01 & $(1.23-4.14)$ \\
\hline \multicolumn{16}{|c|}{ Mental health problems at $\mathrm{TO}$} \\
\hline No $(1$ & 369 & 82.2 & 10.0 & 1 & & & & & & & & & 1 & & \\
\hline Yes & 80 & 17.8 & 52.5 & 9.92 & .00 & $(5.69-17.27)$ & & & & & & & 10.60 & .00 & $(5.56-20.19)$ \\
\hline
\end{tabular}

Note. $\mathrm{MHP}=$ Mental health problems; $\mathrm{TO}=$ baseline; $\mathrm{T} 1=$ follow-up 27 months after baseline; Ref. $=$ reference category; $\mathrm{OR}=$ odd ratio; $95 \% \mathrm{CI}=$ 95\% confidence interval; Adj. OR = adjusted odd ratio.

${ }^{a}$ OR also adjusted for sex, age, education, and smoking. 
Velden, P.G. van der, Kleber, R.J., Grievink, L., Yzermans, J.C. Confrontations with aggression and mental health problems in police officers: the role of organizational stressors, life-events and previous mental-heapt problems. Psychological Trauma: Theory, Research, Practice, and Policy: 2010, 2(2), 135-144

Table 2

Serious Threat and Other Predictors of Mental Health Problems at Follow-Up Among Sub Sample of Police Officers Without Mental Health Problems at Baseline

\begin{tabular}{|c|c|c|c|c|c|c|c|c|c|c|c|c|}
\hline & \multirow[b]{2}{*}{$N$} & \multirow[b]{2}{*}{$\%$} & \multirow{2}{*}{$\begin{array}{l}\% \text { MHP } \\
\text { at T1 }\end{array}$} & \multicolumn{3}{|c|}{ Bi-variate } & \multicolumn{3}{|c|}{ Step 1} & \multicolumn{3}{|c|}{ Step 2} \\
\hline & & & & OR & $p$ & $(95 \% \mathrm{CI})$ & Adj. OR & $p$ & $95 \% \mathrm{CI}$ & Adj. $\mathrm{OR}^{\mathrm{a}}$ & $p$ & $95 \% \mathrm{CI}$ \\
\hline \multicolumn{13}{|c|}{ Being seriously threatened in 12 months before $\mathrm{T} 1$} \\
\hline Not (Ref.) & 96 & 26 & 5.2 & 1 & & & 1 & & & 1 & & \\
\hline Sometimes & 167 & 45.3 & 10.2 & 2.06 & .17 & $(0.74-5.78)$ & 1.72 & .31 & $(0.60-4.94)$ & 1.60 & .40 & $(0.54-4.76)$ \\
\hline Often & 106 & 28.7 & 14.2 & 3.00 & .04 & $(1.05-8.60$ & 2.47 & .10 & $(0.84-7.27)$ & 2.16 & .18 & $(0.71-6.64)$ \\
\hline \multicolumn{13}{|c|}{ Level of organizational stressors: problems with colleagues } \\
\hline Low (Ref.) & 130 & 35.2 & 4.6 & 1 & & 1 & & & 1 & & & \\
\hline Medium & 140 & 37.9 & 7.9 & 1.76 & .28 & $(0.63-4.91)$ & 1.52 & .45 & $(0.51-4.52)$ & 1.74 & .33 & $(0.57-5.30)$ \\
\hline High & 99 & 26.8 & 20.2 & 5.23 & .00 & $(2.01-13.60)$ & 3.76 & .02 & $(1.27-11.08)$ & 4.99 & .01 & $(1.62-15.39)$ \\
\hline \multicolumn{13}{|c|}{ Level of organizational stressors: problems with superiors } \\
\hline Low (Ref.) & 123 & 33.3 & 5.7 & 1 & & & 1 & & & 1 & & \\
\hline Medium & 130 & 35.2 & 7.7 & 1.38 & .53 & $(0.51-3.75)$ & 1.09 & .88 & $(0.38-3.11)$ & 1.18 & .76 & $(0.41-3.41)$ \\
\hline High & 116 & 31.4 & 17.2 & 3.45 & .01 & $(1.40-8.51)$ & 1.74 & .29 & $(0.62-4.89)$ & 1.85 & .26 & $(0.64-5.30)$ \\
\hline \multicolumn{13}{|c|}{ Life-events in 12 months before $\mathrm{T} 1$} \\
\hline No (Ref.) & 188 & 50.9 & 7.4 & 1 & & & & & & 1 & & \\
\hline & 181 & 49.1 & 12.7 & 1.81 & .10 & $(0.90-3.64)$ & & & & 1.76 & .14 & $(0.84-3.71)$ \\
\hline
\end{tabular}

Note. $\mathrm{MHP}=$ Mental health problems; $\mathrm{TO}=$ baseline; $\mathrm{T} 1=$ follow-up, 27 months after baseline Ref. $=$ reference category; $\mathrm{OR}=$ odd ratio; $95 \% \mathrm{CI}=$ $95 \%$ confidence interval; Adj. OR = adjusted odd ratio.

${ }^{a} \mathrm{OR}$ also adjusted for sex, age, education, and smoking.

Table 3

Physical Aggression and Other Predictors of Mental Health Problems at Follow-Up Among Total Sample of Police Officers

\begin{tabular}{|c|c|c|c|c|c|c|c|c|c|c|c|c|c|c|c|}
\hline & \multirow[b]{2}{*}{$N$} & \multirow[b]{2}{*}{$\%$} & \multirow{2}{*}{$\begin{array}{c}\% \text { MHP } \\
\text { at T1 }\end{array}$} & \multicolumn{3}{|c|}{ Bi-variate } & \multicolumn{3}{|c|}{ Step 1} & \multicolumn{3}{|c|}{ Step 2} & \multicolumn{3}{|c|}{ Step 3} \\
\hline & & & & OR & $p$ & $(95 \% \mathrm{CI})$ & Adj. OR & $p$ & $(95 \% \mathrm{CI})$ & Adj. OR & $p$ & $(95 \% \mathrm{CI})$ & Adj. $\mathrm{OR}^{\mathrm{a}}$ & $p$ & $(95 \% \mathrm{CI})$ \\
\hline \multicolumn{16}{|c|}{ Victim of physical aggression in 12 months before T1 } \\
\hline Not (Ref.) & 102 & 22.7 & 14.7 & 1 & & & 1 & & & 1 & & & 1 & & \\
\hline Sometimes & 164 & 36.5 & 16.5 & 1.14 & .70 & $(0.58-2.27)$ & 1.12 & .76 & $(0.55-2.29)$ & 1.17 & .67 & $(0.57-2.42)$ & 1.38 & .47 & $(0.58-3.31)$ \\
\hline Often & 183 & 40.8 & 20.2 & 1.47 & .25 & $(0.76-2.83)$ & 1.22 & .57 & $(0.61-2.42)$ & 1.16 & .68 & $(0.58-2.33)$ & 1.80 & .17 & $(0.78-4.18)$ \\
\hline \multicolumn{16}{|c|}{ Level of organizational stressors: problems with colleagues } \\
\hline Low (Ref.) & 145 & 32.3 & 7.6 & 1 & & & 1 & & & 1 & & & 1 & & \\
\hline Medium & 172 & 38.3 & 15.7 & 1.87 & .12 & $(0.85-4.09)$ & 1.89 & .11 & $(0.86-4.14)$ & 1.99 & .09 & $(0.90-4.39)$ & 1.90 & .16 & $(0.78-4.63)$ \\
\hline High & 132 & 29.4 & 31.1 & 3.91 & .00 & $(1.77-8.65)$ & 3.91 & .00 & $(1.76-8.71)$ & 4.09 & .00 & $(1.82-9.22)$ & 4.63 & .00 & $(1.81-11.85)$ \\
\hline \multicolumn{16}{|c|}{ Level of organizational stressors: problems with superiors } \\
\hline Low (Ref.) & 141 & 31.4 & 9.9 & 1 & & & 1 & & & 1 & & & 1 & & \\
\hline Medium & 161 & 35.9 & 14.3 & 1.51 & .25 & $(0.75-3.07)$ & 1.11 & .79 & $(0.52-2.34)$ & 1.12 & .77 & $(0.53-2.39)$ & 0.92 & .84 & $(0.39-2.14)$ \\
\hline High & 147 & 32.7 & 28.6 & 3.63 & .00 & $(1.88-7.01)$ & 1.99 & .07 & $(0.94-4.18)$ & 1.99 & .07 & $(0.94-4.24)$ & 1.70 & .23 & $(0.72-3.99)$ \\
\hline \multicolumn{16}{|c|}{ Life-events in 12 months before $\mathrm{T} 1$} \\
\hline No (Ref.) & 229 & 51 & 12.7 & 1 & & & & & & 1 & & & 1 & & \\
\hline Yes & 220 & 49 & 22.7 & 2.03 & .01 & $(1.23-3.35)$ & & & & 2.12 & .01 & $(1.25-3.57)$ & 2.30 & .01 & $(1.26-4.20)$ \\
\hline \multicolumn{16}{|c|}{ Mental health problems at $\mathrm{T} 0$} \\
\hline No (Ref.) & 369 & 82.2 & 10.0 & 1 & & & & & & & & & 1 & & \\
\hline Yes & 80 & 17.8 & 52.5 & 9.92 & 0.00 & $(5.69-17.27)$ & & & & & & & 10.71 & .00 & $(5.60-20.47)$ \\
\hline
\end{tabular}

Note. $\mathrm{MHP}=$ Mental health problems; $\mathrm{TO}=$ baseline; $\mathrm{T} 1=$ follow-up. 27 months after baseline; Ref $=$ reference category; $\mathrm{OR}=$ odd ratio; $95 \% \mathrm{CI}=$ 95\% confidence interval; Adj. OR = adjusted odd ratio.

${ }^{a} \mathrm{OR}$ also adjusted for sex, age, education, and smoking. 
Velden, P.G. van der, Kleber, R.J., Grievink, L., Yzermans, J.C. Confrontations with aggression and mental health problems in police officers: the role of organizational stressors, life-events and previous mental-heaplth problems. Psychological Trauma: Theory, Research, Practice, and Policy: 2010, 2(2), 135-144

Table 4

Physical Aggression and Other Predictors of Mental Health Problems at Follow-Up Among Sub Sample of Police Officers Without Mental Health Problems at Baseline

\begin{tabular}{|c|c|c|c|c|c|c|c|c|c|c|c|c|}
\hline & \multirow[b]{2}{*}{$N$} & \multirow[b]{2}{*}{$\%$} & \multirow{2}{*}{$\begin{array}{c}\% \text { MHP } \\
\text { at T1 }\end{array}$} & \multicolumn{3}{|c|}{ Bi-variate } & \multicolumn{3}{|c|}{ Step 1} & \multicolumn{3}{|c|}{ Step 2} \\
\hline & & & & OR & $p$ & $(95 \% \mathrm{CI})$ & Adj. OR & $p$ & $(95 \% \mathrm{CI})$ & Adj. OR & $p$ & $(95 \% \mathrm{CI})$ \\
\hline \multicolumn{13}{|c|}{ Victim of physical aggression in 12 months before $\mathrm{T} 1$} \\
\hline Not (Ref.) & 80 & 21.7 & 7.5 & 1 & & & 1 & & & 1 & & \\
\hline Sometimes & 131 & 35.5 & 8.4 & 1.13 & .82 & $(0.40-3.19)$ & 0.93 & .89 & $(0.32-2.70)$ & 1.05 & .93 & $(0.34-3.23)$ \\
\hline Often & 158 & 42.8 & 12.7 & 1.79 & .23 & $(0.69-4.65)$ & 1.25 & .67 & $(0.46-3.40)$ & 1.23 & .70 & $(0.43-3.49)$ \\
\hline \multicolumn{13}{|c|}{ Level of organizational stressors: problems with colleagues } \\
\hline Low (Ref.) & 130 & 35.2 & 4.6 & 1 & & & 1 & & & 1 & & \\
\hline Medium & 140 & 37.9 & 7.9 & 1.76 & .28 & $(0.63-4.91)$ & 1.47 & .49 & $(0.49-4.39)$ & 1.66 & .37 & $(0.55-5.05)$ \\
\hline High & 99 & 26.8 & 20.2 & 5.23 & .00 & $(2.01-13.60)$ & 3.58 & .02 & $(1.21-10.63)$ & 4.78 & .01 & $(1.55-14.76)$ \\
\hline \multicolumn{13}{|c|}{ Level of organizational stressors: problems with superiors } \\
\hline Low (Ref.) & 123 & 33.3 & 5.7 & 1 & & & 1 & & & 1 & & \\
\hline Medium & 130 & 35.2 & 7.7 & 1.38 & .53 & $(0.51-3.75)$ & 1.12 & .84 & $(0.39-3.19)$ & 1.21 & .72 & $(0.42-3.53)$ \\
\hline High & 116 & 31.4 & 17.2 & 3.45 & .01 & $(1.40-8.51)$ & 1.90 & .23 & $(0.67-5.39)$ & 1.99 & .21 & $(0.68-5.81)$ \\
\hline \multicolumn{13}{|c|}{ Life-events in 12 months before $\mathrm{T} 1$} \\
\hline No (Ref.) & 188 & 50.9 & 7.4 & 1 & & & & & & 1 & & \\
\hline Yes & 181 & 49.1 & 12.7 & 1.81 & .10 & $(0.90-3.64)$ & & & & 1.82 & .12 & $(0.86-3.85)$ \\
\hline
\end{tabular}

Note. $\mathrm{MHP}=$ Mental health problems; $\mathrm{TO}=$ baseline; $\mathrm{T} 1=$ follow-up, 27 months after baseline Ref. $=$ reference category $; \mathrm{OR}=$ odd ratio; $95 \% \mathrm{CI}=$ $95 \%$ confidence interval; Adj. OR = adjusted odd ratio.

${ }^{a} \mathrm{OR}$ also adjusted for sex, age, education, and smoking. 